\title{
DBPiE \\ Effects of Water-Soluble Calcium Supplements Made from Eggshells and Oyster Shells on the Calcium Metabolism of Growing Rats
}

저자

(Authors)

출처

(Source)

\section{발행처}

(Publisher)

URL

APA Style

이용정보

(Accessed)

Se-Young Jang, Yong-Jin Jeong, Taeg-Kyu Kwon, Ji-Hyung Seo

한국식품영양과학회

The korean Society of Food Science and Nutrition

http://www.dbpia.co.kr/Article/NODE01396388

계명대학교

114.71.5.212
Preventive Nutrition and Food Science 15(1), 2010.3, 78-82 (5 pages)

Se-Young Jang, Yong-Jin Jeong, Taeg-Kyu Kwon, Ji-Hyung Seo (2010). Effects of WaterSoluble Calcium Supplements Made from Eggshells and Oyster Shells on the Calcium Metabolism of Growing Rats. Preventive Nutrition and Food Science, 15(1), 78-82.

2016/01/13 14:00 (KST)

\section{저작권 안내}

DBpia에서 제공되는 모든 저작물의 저작권은 원저작자에게 있으며, 누리미디어는 각 저작물의 내용을 보증하거나 책임을 지지 않습니다.

이 자료를 원저작자와의 협의 없이 무단게재 할 경우, 저작권법 및 관련법령에 따라 민, 형사상의 책임을 질 수 있습니다.

\section{Copyright Information}

The copyright of all works provided by DBpia belongs to the original author(s). Nurimedia is not responsible for contents of each work. Nor does it guarantee the contents.

You might take civil and criminal liabilities according to copyright and other relevant laws if you publish the contents without consultation with the original author(s). 


\title{
Effects of Water-Soluble Calcium Supplements Made from Eggshells and Oyster Shells on the Calcium Metabolism of Growing Rats
}

\author{
- Research Note - \\ Se-Young Jang ${ }^{1}$, Yong-Jin Jeong', Taeg-Kyu Kwon', and Ji-Hyung Seo ${ }^{3 \dagger}$ \\ ${ }^{1}$ Department of Food Science and Technology, Keimyung University, and Keimyung Foodex Co., Ltd, Daegu 704-701, Korea \\ ${ }^{2}$ Department of Immunology, College of Medicine, Keimyung University, Daegu 700-712, Korea \\ ${ }^{3}$ Division of Food, Beverage \& Culinary Arts, Yeungnam College of Science \& Technology, Daegu 705-703, Korea
}

\begin{abstract}
This study investigated the effects of water-soluble calcium supplements manufactured with eggshells and oyster shells on growing rats. The aim was to review the potential use of food wastes as materials for water-soluble calcium supplements as compared to water-soluble calcium supplements made from imported seaweed powder. When expenimental animals were administered three types of water-soluble calcium supplements orally for six weeks, the senum calcium level of the seaweed calcium supplement group were significantly higher than that of eggshell or oyster shell-denived calcium, but blood alkali phosphatase activity, osteocalcin and urine crosslink levels were not different in the three types of calcium supplements. Bone mineral density and bone mineral content in spine, femur and tibia also were not significantly different among the groups. However, when considering body weight of each group, bone mineral density and bone mineral content of the femur were significantly higher in the oyster shell calcium supplement group. These results suggest that at least on a short-tem basis, the effect of calcium supplements prepared from eggshell and oyster shell are similar to the effects of seaweed calcium supplements.
\end{abstract}

Key words: calcium supplements, water-soluble calcium, eggshell, oyster shell, calcium absorption

\section{INTRODUCTION}

According to a 2005 Korea national health \& nutrition examination survey (1), only $79.0 \%$ of the recommended average calcium intake per day (553.1 mg) was taken by Koreans. Calcium is a main component of bones and teeth and is related to neurotransmission, muscle movement, blood clotting and hormone secretion. A long-term calcium deficiency can increase the likelihood of hypertension (2), stroke (3) and colon cancer (4), as well as skeletal diseases (5). Although milk, cheese and anchovies contain a lot of calcium, the majority of calcium intake by Koreans comes from vegetables (6). Therefore many Koreans, especially adolescents, the elderly and osteoporosis patients tend to supplement the lack of calcium by using calcium supplement or calcium enriched foods.

Calcium carbonate, a water-insoluble calcium has been widely used as a representative calcium supplement as it can be produced on a large scale at low cost. However, as some reports found that more soluble calcium supplements had more effective absorption into the body (7-10), the calcium absorption rate as well as calcium content has been recognized as critical factors in calcium supplement usage. Commercial calcium supplements are divided into synthetic supplements such as calcium carbonate, calcium lactate and calcium citrate, and natural supplements including whey calcium and seaweed powder. In a previous study, the authors had studied the uses of water-soluble calcium supplement produced with seaweed powders in growing rats (11). The seaweed powder based, water-soluble calcium supplement was expected to be more beneficial to bone mineral density in terms of weight bearing on the skeleton than the insoluble calcium supplement. However, the cost of seaweed powder-based calcium is relatively high because most of it is imported, so other natural calcium materials are being developed as potential substitutes.

This study investigated the effects of intake of water-soluble calcium supplements produced with eggshells and oyster shells to determine the possibility of using these waste resources as cost-effective materials for calcium supplements.

\section{MATERIALS AND METHODS}

Experimental animals and diet

In this study, growing female rats, for which the ad-

${ }^{\dagger}$ Corresponding author. E-mail: seojh@ync.ac.kr

Phone: +82-53-650-9346, Fax: +82-53-650-9346 
ministration of liquid calcium supplement was feasible and calcium metabolism was active, were selected as experimental animals. Twenty one female Sprague-Dawley rats weighing an average of $90 \mathrm{~g}$ were purchased (Danhan Biolink Co., Seoul, Korea) and adapted on rat chow (Sam Yang Co., Seoul, Korea) for one week. Then they were randomly divided into 3 groups according to body weight, 7 animals per group, and fed experimental diets for 6 weeks. During the experiment period, the animal room was maintained $22 \pm 2^{\circ} \mathrm{C}$ and $55 \pm 5 \%$ relative humidity with a $12 \mathrm{hr}$ light/dark cycle. Experimental diets and deionized water were offered ad libitum. A calcium-free AIN-93G (Ca free) diet was prepared (Table 1) and fed to all experimental rats. The three experimental groups consisted one that was supplied water-soluble calcium supplement made from commercial seaweed powder (Aqua-Ca, Marigot Group Celtic Sea Minerals Ltd., Cork, Ireland), one that was supplied water-soluble calcium supplement made from eggshells (ES-Ca), and one that was supplied water-soluble calcium supplement made from oyster shells (OS-Ca). The control group in this study was the one receiving the seaweed calcium supplement because the effect of this supplement has been previously documented (11).

\section{Administration of calcium supplements}

Three water-soluble calcium supplements $(60 \mathrm{mg} / \mathrm{mL}$, over $90 \%$ ionizing ratio) which were prepared from calcium materials (seaweed powder, eggshells and oyster shells) by soaking in vinegar (12) were provided by Kyemyeong Foodex Co. (Daegu, Korea). Each calcium supplement was administered once a day at a constant time, $10 \mathrm{~mL} / \mathrm{kg}$ body weight.

\section{Dietary consumption rate and weight measurement}

Dietary consumption rate was measured once a day, and body weight was measured two times a week at the same times, and the diet efficiency was calculated by

Table 1. Composition of experimental diet (g/kg of diet)

\begin{tabular}{lc}
\hline Ingredient & Calcium free diet \\
\hline Casein & 200 \\
Corn starch & 592.486 \\
Sucrose & 100 \\
Soybean oil & 70 \\
Cellulose & 50 \\
$t$-Butylhydroquinone & 0.014 \\
Min-mix $^{1)}$ & 35 \\
Vit-mix & \\
L-Cystine & 10 \\
Choline bitartrate & 3 \\
\hline
\end{tabular}

${ }^{1)}$ AIN-93G mineral mixture (Ca free).

${ }^{2)}$ AIN-93VX vitamin mixture. dividing the weight gain during the experimental period by the diet consumption amount.

\section{Sample collection}

After 6 weeks of oral administration, rats were fasted overnight and the urine collected, then they were anesthetized with ether and sacrificed. After the blood collected from the aorta was centrifuged at 3,000 rpm for $20 \mathrm{~min}$, the serum was separated and stored frozen at $-70^{\circ} \mathrm{C}$.

\section{Biochemical analysis}

Serum calcium content was measured by an automatic absorption analyzer applying the TECHNICON CHEMTM system (Alliance Instruments, Paris, France) and alkaline phosphatase (ALP) activity was analyzed using a kit based on the Kind and King method (13). Serum osteocalcin content was analyzed by an osteocalcin radioimmuno-assay kit (Brahams Co., MI, USA). Deoxypyridinoline and creatinine content were analyzed using a collagen crosslink kit (Metra biosystems Inc., CA, USA) by ELISA. The crosslink value was the value obtained by dividing deoxypyridinoline content by creatinine content.

\section{Bone mineral density and bone mineral content meas- urement}

At 6 weeks of oral administration, the anesthetic pentobabobital sodium (Han Lim Pharmaceuticals, Seoul, Korea) was injected intraperitoneally, at $1 \mathrm{~mL} / \mathrm{kg}$ dose. The bone mineral density (BMD) and bone mineral content (BMC) of the spine, the femur, and the tibia were measured using the dual energy x-ray absorptionmetry (DEXA) FIXImus (LUNAR, Madison, WI, USA).

\section{Statistical analysis}

Experiment results were presented as a mean and standard deviation using the SPSS program (13.0), the comparison among experiment groups was performed by one way ANOVA, and their significance was validated by Duncan's multiple range test $(p<0.05)$.

\section{RESULTS AND DISCUSSION}

\footnotetext{
Diet and calcium intake, weight gain, and food efficiency ratio

Dietary intake, calcium intake, the amount of weight gain and dietary efficiency (food efficiency ratio, FER) of the experimental animals taking oral water-soluble calcium supplements made of seaweed powders, eggshells and oyster shells over the course of six weeks are shown in Table 2. While the average dietary intake per day was significantly high in the eggshell calcium supplement group $(\mathrm{p}<0.05)$, weight gain was not sig-
} 
Table 2. Diet intake, total calcium intake, body weight gain and food efficient ratio (FER) of rats fed different calcium supplements

\begin{tabular}{ccccc}
\hline Group $^{1)}$ & Dietary intake (g/day) & Total calcium intake (g/6 weeks) & Weight gain (g/day) & FER ${ }^{4)}$ \\
\hline Aqua-Ca & $13.63 \pm 0.46^{\mathrm{b} 2)}$ & $\left.5.10 \pm 0.45^{\mathrm{NS} 3}\right)$ & $2.07 \pm 0.41^{\mathrm{NS}}$ & $0.15 \pm 0.02^{\mathrm{a}}$ \\
ES-Ca & $15.00 \pm 0.89^{\mathrm{a}}$ & $4.95 \pm 0.42$ & $2.01 \pm 0.36$ & $0.13 \pm 0.02^{\mathrm{ab}}$ \\
OS-Ca & $14.13 \pm 0.65^{\mathrm{b}}$ & $5.05 \pm 0.38$ & $1.82 \pm 0.32$ & $0.12 \pm 0.02^{\mathrm{b}}$ \\
\hline
\end{tabular}

${ }^{1)}$ Aqua-Ca (control): rats supplied soluble calcium supplement made of commercial seaweed powder (AquaCal), ES-Ca: rats supplied soluble calcium supplement made of eggshell, OS-Ca: rats supplied soluble calcium supplement made of oyster shell.

${ }^{2)}$ Means with different superscripts within the column are significantly different at $\mathrm{p}<0.05$.

${ }^{3)}$ Not significantly different.

${ }^{4)} \mathrm{FER}=$ weight gain/dieary intake.

nificantly different among the three groups. The food efficiency ratio (FER) was significantly higher in the seaweed calcium supplement group than in oyster shell calcium supplement group. Dietary intake could be affected by trace components that might differ in each of the calcium supplements, causing a change in taste or appetite, however more research is needed. The total calcium intake was not significantly different among the experimental groups.

\section{Senum and unine composition}

The results for the serum calcium content and bone formation markers, alkaline phosphatase and osteocalcin, are shown in Table 3. Serum calcium in the seaweed calcium supplement group was $11.85 \mathrm{mg} / \mathrm{dL}$ and significantly different from the other groups. There was no significant difference in serum calcium between the egg-

Table 3. Serum calcium, alkaline phosphatase (ALP) and osteocalcin of rats fed different calcium supplements

\begin{tabular}{cccc}
\hline Group $^{1)}$ & $\begin{array}{c}\text { Serum calcium } \\
(\mathrm{mg} / \mathrm{dL})\end{array}$ & $\begin{array}{c}\text { ALP } \\
(\mathrm{IU} / \mathrm{L})\end{array}$ & $\begin{array}{c}\text { Osteocalcin } \\
(\mathrm{ng} / \mathrm{mL})\end{array}$ \\
\hline Aqua-Ca & $11.85 \pm 0.43^{\mathrm{a} 2)}$ & $\left.431.83 \pm 61.82^{\mathrm{NS} 3}\right)$ & $0.75 \pm 0.51^{\mathrm{NS}}$ \\
ES-Ca & $11.43 \pm 0.50^{\mathrm{b}}$ & $404.66 \pm 82.76$ & $0.74 \pm 0.29$ \\
OS-Ca & $11.32 \pm 0.54^{\mathrm{b}}$ & $404.50 \pm 77.22$ & $0.62 \pm 0.38$ \\
\hline
\end{tabular}

${ }^{1)}$ Aqua-Ca (control): rats supplied soluble calcium supplement made of commercial seaweed powder (AquaCal), ES-Ca: rats supplied soluble calcium supplement made of eggshell, OS-Ca: rats supplied soluble calcium supplement made of oyster shell.

${ }^{2)}$ Means with different superscripts within the column are significantly different at $\mathrm{p}<0.05$.

${ }^{3)}$ Not significantly different. shell calcium supplement group and the oyster shell calcium supplement group. The levels of alkaline phosphatase and osteocalcin among three groups were not significantly different. Alkaline phosphatase induces bone formation through osteoblast activation $(14,15)$, leading to the secretion of osteocalcin, a specific protein of bone matrix, which is recognized as an index for bone turnover as well as bone formation (16). According to the previous study (11), supplementation with the water-soluble calcium manufactured with seaweed powder was expected to positively affect skeletal health, and both the eggshell and the oyster shell calcium supplements were thought to act similarly. However high concentration of serum calcium would protect bone resorption and accelerate calcium usage in cells such as osteoblasts (17). Considering the homeostasis of the serum calcium concentrations, a long-term effect of calcium supplementation is expected to be more pronounced for the seaweed calcium supplement. In addition, serum calcium could be affected by the ionization rate of the calcium supplement (18), however, more research on that is needed.

Table 4 reveals that there was no significant difference in the levels of urine deoxypyridinoline and creatinine among the three kinds of calcium supplemented groups. Deoxypyridinoline in the skeleton is excreted in the urine with collagen by-products as a result of osteoclast action (19). Because of the diurnal variations in urine deoxypyridinoline levels, crosslink values based on creatinine levels are used to monitor bone resorption (20). Considering the results for crosslink value, we speculate

Table 4. Urine deoxypyridinoline, creatinine and crosslink value of rats fed different calcium supplements

\begin{tabular}{cccc}
\hline Group $^{1)}$ & Deoxypyridinoline $(\mathrm{nM})$ & Creatinine $^{(\mathrm{mM})}$ & Crosslink value $^{4)}(\mathrm{nM} / \mathrm{mM})$ \\
\hline Aqua-Ca & $1136.81 \pm 276.66^{2) \mathrm{NS} 3}$ & $6.67 \pm 2.37^{\mathrm{NS}}$ & $171.84 \pm 49.18^{\mathrm{NS}}$ \\
ES-Ca & $1357.53 \pm 259.20$ & $7.74 \pm 2.02$ & $175.23 \pm 29.74$ \\
OS-Ca & $1223.76 \pm 159.72$ & $7.54 \pm 2.03$ & $163.75 \pm 34.36$ \\
\hline
\end{tabular}

\footnotetext{
${ }^{1)}$ Aqua-Ca (control): rats supplied soluble calcium supplement made of commercial seaweed powder (AquaCal), ES-Ca: rats supplied soluble calcium supplement made of eggshell, OS-Ca: rats supplied soluble calcium supplement made of oyster shell. ${ }^{2)}$ Mean \pm SD.

${ }^{3)}$ Not significantly different.

${ }^{4)}$ Crosslink value=deoxypyridinoline/creatinine.
} 
Table 5. Bone mineral density (BMD) and bone mineral content (BMC) of rats fed different calcium supplements

\begin{tabular}{cclccc}
\hline Bone & Group $^{1)}$ & BMD $\left(\mathrm{g} / \mathrm{cm}^{2}\right)$ & BMD $\left(\mathrm{g} / \mathrm{cm}^{2}\right) / 100 \mathrm{~g}$ wt & BMC $(\mathrm{g})$ & $\mathrm{BMC}\left(\mathrm{g} / \mathrm{cm}^{2}\right) / 100 \mathrm{~g}$ wt \\
\hline \multirow{3}{*}{ Spine } & Aqua-Ca & $\left.0.138 \pm 0.018^{\mathrm{NS} 2}\right)$ & $0.057 \pm 0.010^{\mathrm{NS}}$ & $0.341 \pm 0.046^{\mathrm{NS}}$ & $0.142 \pm 0.021^{\mathrm{NS}}$ \\
& ES-Ca & $0.136 \pm 0.014$ & $0.057 \pm 0.006$ & $0.345 \pm 0.056$ & $0.146 \pm 0.019$ \\
& OS-Ca & $0.136 \pm 0.009$ & $0.059 \pm 0.004$ & $0.344 \pm 0.071$ & $0.159 \pm 0.017$ \\
\hline \multirow{3}{*}{ Femur } & Aqua-Ca & $0.177 \pm 0.023^{\mathrm{NS}}$ & $0.073 \pm 0.006^{\mathrm{b} 3)}$ & $0.332 \pm 0.042^{\mathrm{NS}}$ & $0.138 \pm 0.010^{\mathrm{b}}$ \\
& ES-Ca & $0.178 \pm 0.016$ & $0.075 \pm 0.008^{\mathrm{ab}}$ & $0.337 \pm 0.040$ & $0.143 \pm 0.015^{\mathrm{b}}$ \\
& OS-Ca & $0.183 \pm 0.093$ & $0.080 \pm 0.006^{\mathrm{a}}$ & $0.357 \pm 0.024$ & $0.156 \pm 0.010^{\mathrm{a}}$ \\
\hline \multirow{3}{*}{ Tibia } & Aqua-Ca & $0.120 \pm 0.009^{\mathrm{NS}}$ & $0.050 \pm 0.005^{\mathrm{NS}}$ & $0.284 \pm 0.041^{\mathrm{NS}}$ & $0.118 \pm 0.018^{\mathrm{NS}}$ \\
& ES-Ca & $0.118 \pm 0.007$ & $0.050 \pm 0.004$ & $0.284 \pm 0.031$ & $0.120 \pm 0.010$ \\
& OS-Ca & $0.117 \pm 0.007$ & $0.051 \pm 0.004$ & $0.281 \pm 0.041$ & $0.122 \pm 0.015$ \\
\hline
\end{tabular}

${ }^{1)}$ Aqua-Ca (control): rats supplied soluble calcium supplement made of commercial seaweed powder (AquaCal), ES-Ca: rats supplied soluble calcium supplement made of eggshell, OS-Ca: rats supplied soluble calcium supplement made of oyster shell. ${ }^{2)}$ Not significantly different.

${ }^{3)}$ Means with different superscripts within the column are significantly different at $\mathrm{p}<0.05$.

no significant difference of bone resorption among the three calcium supplemented groups.

\section{Bone mineral density (BMD) and bone mineral con- tent (BMC)}

Table 5 shows the lack of a significant difference in the BMD and BMC of the spine, femur and tibia after six weeks of calcium supplementation across the groups. Therefore, the eggshell calcium supplement and the oyster shell calcium supplements were considered not to be significantly different from the seaweed calcium supplement in bone metabolism. In addition, when realistic skeletal health condition considering weight bearing was compared (21), both of bone density and bone content per $100 \mathrm{~g}$ of body weight in femur were high in the oyster shell group. Lee and Kim (22) reported that the amount of calcium intake affected the mineral composition of femur more than the spine. Schaafsma et al. (23) also reported that intake of enriched eggshell powder supplement increased BMD of the femoral neck in post-menopausal women. Hence the oyster shell calcium supplement might act on femur specifically.

When each calcium supplement was taken on a short-term basis, the calcium supplementation effect of the eggshell calcium supplement and the oyster shell calcium supplement were expected to be similar to the seaweed calcium supplement. Hereafter, studies on trace component and specificity of action of each calcium supplement are necessary.

\section{REFERENCES}

1. Korea Health Industry Development Institute (KHIDI). 2006. The third Korea national health \& nutrition examination survey (KNHANES III)-Nutrition survey ( $I$ ). Ministry of Health \& Welfare, Seoul, Korea. p 226.

2. Miller GD, DiRienzo DD, Reusser ME, McCarron DA. 2000. Benefits of dairy product consumption on blood pressure in human: A summary of the biomedical literature. J Am Coll Nutr 19: 147S-164S.

3. Massey LK. 2001. Dairy food consumption, blood pressure and stroke. $J$ Nutr 131: 1875-1878.

4. Scalmati A, Lipkin M, Newmark HC. 1992. Vitamin D and colon cancer. In Clinics in Applied Nutrition. Chernoff R, Heaney RP, eds. Andover Med., MA, USA. p 67-74.

5. Bryant RJ, Cadogan J, Weaver CM. 1999. The new dietary reference intakes for calcium: Implications for osteoporosis. J Am Coll Nutr 18: 406S-412S.

6. Korea Health Industry Development Institute (KHIDI). 2006. The third Korea national health \& nutrition examination survey (KNHANES III) - Nutrition survey (II). Ministry of Health \& Welfare, Seoul, Korea. p 215.

7. Sakhaee K, Bhuket T, Adams-Huet B, Sudhaker RD. 1999. Meta-analysis of calcium bioavailability: A comparison of calcium citrate with calcium carbonate. Am $J$ Ther 6: 313-321.

8. Heller HJ, Greer LG, Haynes SD, Pondexter JR, Pak CY. 2000. Pharmacokinetic and pharmacodynamic comparison of two calcium supplements in postmenopausal women. J Clin Pharmacol 40: 1237-1244.

9. Hanzlik RP, Fowler SC, Fisher DH. 2005. Relative bioavailability of calcium from calcium formate, calcium citrate, and calcium carbonate. J Pharmacol Exp Ther 313: 1217-1222.

10. Allen LH. 1982. Calcium bioavailability and absorption: A review. Am J Clin Nutr 35: 783-808.

11. Jang SY, Kwon TK, Jeong YJ, Seo JH, Park YM. 2007. The effect of water soluble calcium supplements on calcium metabolism and bone metabolism of growing rats. Korean J Food Sci Nutr 12: 217-221.

12. Jang SY, Baek CH, Jeong KH, Park NY, Jeong YJ. 2005. Effect of vinegar on the solubility of calcium. Korean $J$ Food Preserv 12: 112-116.

13. Kind PRN, King ER. 1954. Estimation of plasma phosphatase by determination of hydrolyzed with amino antipyrene. J Clin Pathol 3: 332-334.

14. Hamalainen MM. 1994. Bone repair in calcium-deficient rats: Comparison of xylitol+calcium carbonate with calcium carbonate, calcium lactate and calcium citrate on the repletion of calcium. Am J Nutr 124: 874-881.

15. Kleerekoper M. 1996. Biochemical markers of bone remodeling. Am J Med Sci 312: 270-277.

16. Delmas PD. 1993. Biochemical markers of bone turnover: 
Theoretical consideration and clinical use in osteoporosis. Am J Med 95 (supple 5A): 11S-16S.

17. Louis VA. 1988. Calcium and phosphorus. In Modern Nutrition in Health and Disease. Maurice ES, Vernon RY, eds. Lea \& Febiger, Philadelphia, USA. p 142-154.

18. Lee SK, Kim YT. 2003. Studies of egg-shell calcium (II): A study on absorption rate of egg-shell calcium in rat. Kor J Fd Hyg Safety 18: 73-78.

19. Eyre DR. 1996. Biochemical markers of bone turnover. In Primer on the metabolic bone diseases and disorder of mineral metabolism. Favus MJ, ed. 3rd ed. Raven Press, New York, USA. p 114-118.

20. Eyre DR, Koob TJ, Van ness KP. 1984. Quantitation of hydroxypyridinium crosslinks in collagen by high-per- formance liquid chromatography. Anal Biochem 137: 380388.

21. Choi MJ, Jo HJ. 2003. Effects of soy protein and isoflavones on bone mineral density in growing female rat. Kor J Nutr 36: 359-367.

22. Lee YS, Kim EM. 1998. Effect of ovariectomy and dietary calcium levels on bone metabolism in rats fed low calcium diet during growing period. Kor J Nutr 31: 279-288.

23. Schaafsma A, van Doormaal JJ, Muskiet FAJ, Hofstede GJH, Pakan I, Veer E. 2002. Positive effects of a chicken eggshell powder-enriched vitamin-mineral supplement on femoral neck bone mineral density in healthy late post-menopausal Dutch women. British J Nutr 87: 267275.

(Received January 18, 2010; Accepted March 13, 2010) 